\title{
Amyloidosis
}

\author{
M F Khan, R H Falk
}

\begin{abstract}
Amyloidosis is not a single disease but a series of diseases in which there is extracellular deposition of a protein which, although it may be derived from different and unrelated sources, folds into a $\beta$ pleated sheet.

There have recently been significant advances in elucidating the pathogenesis and in the treatment of this group of disorders. By identifying the source of precursor protein, treatment is aimed at eliminating or reducing the extent of deposition and is tailored for each patient.

Early diagnosis is required for the optimal effect of treatment on patient survival and quality of life. An increased awareness among physicians of the spectrum of the disease and tools to aid its diagnosis is of increasing importance.

(Postgrad Med F 2001;77:686-693)
\end{abstract}

Keyword: amyloidosis

Although necropsy data consistent with amyloidosis were reported over 300 years ago, the term amyloid was only coined in the mid-19th century to describe the "lardaceous" nature of affected organs. ${ }^{12}$ Bennhold introduced Congo red in 1922 and showed the characteristic red staining of amyloid in normal light but apple green birefringence under polarised light microscopy, which remains the gold standard for diagnosis. ${ }^{3}$ Later electron microscopy demonstrated that amyloid was a fibrous protein ${ }^{4}$ with a unique cross $\beta$ pattern on $x$ ray diffraction. ${ }^{56}$ The amyloidoses are thus a heterogeneous group of disorders related by the deposition of proteins that share a remarkably similar and stable core structure of $\beta$ sheets.

\section{Amyloid composition}

The $\beta$ sheet, likely to be responsible for its typical staining properties, is not the only common constituent of amyloid deposits. The amyloid $\mathrm{P}$ component is a glycoprotein that comprises up to $15 \%$ of the amyloid deposit, probably contributing to its relative stability. Clinically, it has been radiolabelled allowing

Submitted 10 October 2000 Accepted 9 March 2001

Table 1 Classification

\begin{tabular}{lll}
\hline Type & Fibril & Examples/associated features \\
\hline AL & Monoclonal immunoglobulin light chain & $\begin{array}{l}\text { Plasma cell dyscrasia } \\
\text { Myeloma associated } \\
\text { Rheumatoid arthritis } \\
\text { Tuberculosis }\end{array}$ \\
AA (secondary) & Amyloid A protein & Familial Mediterranean fever \\
& & Met 30, Ala 60, Ile 122 \\
Familial types: & Transthyretin & Arg 26 \\
ATTR & Apoliproprotein A-1 & Leu 554 \\
AapoA-1 & Fibrinogen A- $\alpha$ L & Chronic haemodialysis \\
AFib & $\beta 2$ microglobulin & Alzheimer's disease \\
A $\beta 2 M$ & $\beta$ protein & \\
A $\beta$ & & \\
\hline
\end{tabular}

\section{Learning points}

- Amyloid proteins are composed of $\beta$ pleated sheets, which stain with Congo red appearing red in normal light but apple green under polarised light microscopy.

- The modern classification is based on the nature of the precursor protein.

- Several forms of hereditary amyloidosis have recently been discovered. They include a substitution of isoleucine at codon 122 that is carried by $3.9 \%$ of the black population.

- Symptoms of renal disease such as proteinuria or the nephrotic syndrome associated with cardiac disease or an autonomic neuropathy must make a physician very suspicious of systemic amyloidosis.

- Advances in the understanding of the amyloidoses have led to treatment options and the possibility of cure: liver transplantation for ATTR amyloidoses, high dose melphalan and bone marrow stem cell transplantation for AL amyloidosis, reducing the inflammatory response in AA amyloidosis (for example, colchicine in familial Mediterranean fever).

scintigraphic imaging. ${ }^{7}$ Various glycosaminoglycans, universally present, and the amyloid enhancing factor are believed to enhance fibrillogenesis. ${ }^{89}$

\section{Classification and epidemiology}

The unique aspect of the amyloid deposits is the nature of the precursor protein that forms the fibrillar deposit. This is now the basis of the accepted classification of the amyloidoses. ${ }^{10}$ The more common of these conditions along with their precursor proteins are discussed below and summarised in table 1 .

Although amyloidosis is a rare disease with an incidence of 12 cases per million population per year, this figure is no less than a number of conditions that are more widely recognised (table 2) including chronic myeloid leukaemia and the Guillain-Barré syndrome. The incidence of the familial amyloidoses is unknown but represents $10 \%$ to $20 \%$ of AL cases seen in referral centres. ${ }^{11}$

\section{AL amyloidosis}

Unstable monoclonal immunoglobulin light chains, produced by a plasma cell dyscrasia, lead to the formation and deposition of fibrils. The fibrils are derived from the N-terminal region of monoclonal light chains and consist of a portion of the variable region of either $\kappa$ or $\lambda$ light chains or the whole molecule (fig 1 ). ${ }^{12}$ 
Table 2 Incidence of AL amyloidosis compared to other conditions

\begin{tabular}{ll}
\hline Condition & Incidence/million population \\
\hline AL amyloidosis & 12 \\
Chronic myeloid leukaemia & 13 \\
Guillain-Barré syndrome & 12 \\
Multiple myeloma & 40
\end{tabular}

Note: prevalence of AL is lower than these conditions due to a shorter survival.

Unlike multiple myeloma and monoclonal gammopathies where $\kappa$ chains are the more frequent, in $\mathrm{AL}$ the ratio of $\kappa$ to $\lambda$ light chains has been found to be $1: 3 .^{11}$ These light chains deposit most frequently in the kidney and the heart. At presentation renal disease, usually proteinuria with the nephrotic syndrome, is found in $65 \%$ of AL patients whereas cardiac involvement, seen in one third of presenting cases, is the cause of death in up to one half of patients. ${ }^{1314}$ The clinical features of right heart failure predominate (raised venous pressure, hepatomegaly, peripheral oedema) but the biventricular nature of deposition may be evidenced by symptoms of dyspnoea on effort.

\section{AA amyloidosis}

The amyloid associated with chronic inflammatory conditions such as tuberculosis or rheumatoid arthritis is composed of protein AA, a 76 amino acid molecule. ${ }^{15}$ In contrast to the variability of the AL protein, the amino acid sequence of the AA protein is highly conserved. ${ }^{16}$ It is derived from an acute phase reactant, serum amyloid A, produced in response to inflammation under regulation of cytokines including tumour necrosis factor $(\mathrm{TNF}-\alpha)$.

Why AA amyloidosis manifests in only a proportion of those with chronically high levels of serum amyloid A is not fully understood. Although experimentally certain portions of the serum amyloid A molecule have been shown to be more amyloidogenic, ${ }^{17}$ factors other than the protein structure probably play important roles in the rate of fibril deposition in clinical disease. Studies have suggested that amyloid fibril formation can be increased by proteolysis, the presence of amyloid enhancing factor and by basement membrane heparin sulphate proteoglycan. ${ }^{18}$

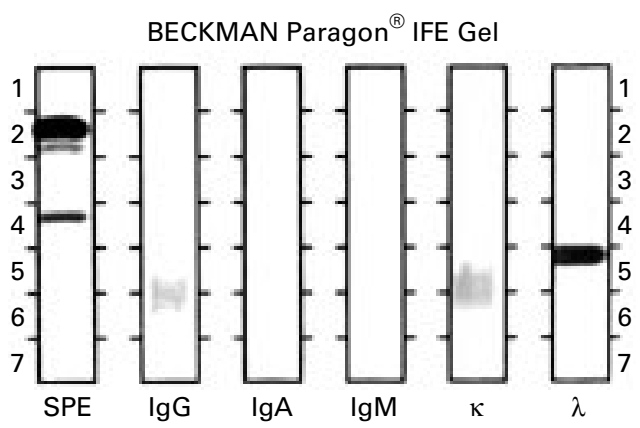

Figure 1 Serum immunofixation electrophoresis (IFE). Serum proteins of differing molecular weights are represente as bands in the serum protein electrophoresis (SPE) strip (left). The prominent band in the $\lambda$ component represents free monoclonal light chains, the precursors for AL amyloidosis.
With the relative decline of infectious diseases in the West, the inflammatory arthritidies are now the commonest cause of AA amyloidosis. Renal disease is the most common manifestation, although deposition may be extensive with no symptoms. ${ }^{19}$ Hepatomegaly or splenomegaly is often associated with this condition $^{20}$ and carries a worse prognosis.

\section{Familial amyloidosis}

The hereditary forms of amyloidosis are autosomal dominant diseases in which an inherited variant protein causes the production of amyloid fibrils. The most commonly inherited mutations occur in transthyretin, although mutations in a number of other serum proteins such as apolipoprotein A-1, fibrinogen, and gelsolin are also recognised..$^{21-23}$

Transthyretin is a protein synthesised primarily in the liver and is responsible for transporting vitamin $\mathrm{A}$ and thyroxine. The protein has potential to fold into a $\beta$ pleated sheet, a characteristic that may be increased pathologically by an unstable inherited variation. There are over 60 such mutations, ${ }^{24}$ the most common being substitutions of methionine for valine at position 30 (Met 30) - of universal occurrence - and alanine for threonine at position 60 (Ala 60), most commonly in those of Anglo-Saxon and Celtic ancestry. ${ }^{25}{ }^{26}$ It has recently been estimated that almost $4 \%$ of the black population may carry an amyloidogenic substitution of isoleucine for valine at position 122 (Ile 122), although phenotypic prevalence is as yet unknown. ${ }^{27} 28$

Clinically, these forms of amyloidoses are manifest with significant neuropathic involvement and have been termed the familial amyloidotic polyneuropathies. Symptom onset is often a consequence of peripheral sensorimotor neuropathy, autonomic dysfunction, or cardiomyopathy.

\section{Dialysis related amyloidosis (Aß2M)}

In haemodialysis patients, $\beta 2$ microglobulin, part of the class I major histocompatibility complex antigen, fails to cross the dialysis membrane resulting in the formation of amyloid fibrils. ${ }^{29}$ This may result in $\mathrm{A} \beta 2 \mathrm{M}$ with deposition in joints (resulting in arthritis), periarticular tissue (resulting in carpal tunnel syndrome), and in bones (resulting in cysts).

\section{Cerebral amyloidosis}

Although not considered in the family of the amyloidoses, Alzheimer's disease, Down's syndrome, and the hereditary amyloid angiopathy of Dutch type, are associated with a form of amyloid in which the $\beta$ protein, ${ }^{30}$ derived from $\beta$ amyloid precursor protein, is deposited. How the $\beta$ protein fragments or the amyloid fibrils formed contribute to neuronal dysfunction is controversial. The fact that Alzheimer's, identical to that of the sporadic type, can be caused by mutations of $\beta$ amyloid precursor protein suggests a primary role. This is supported by the observation that recently discovered mutations in familial Alzheimer's are associated with the most amyloidogenic forms of $\beta$ protein. ${ }^{31}$ 
Table 3 Differential diagnoses

Renal failure with normal sized kidneys:
Amyloidosis
Diabetes mellitus
Sarcoidosis
Lymphoma
Multiple myeloma
Capillary vascular fragility:
Amyloidosis
Scurvy
Ehlers-Danlos syndrome
Macroglossia:
AL amyloidosis
Down's syndrome
Neoplasia-lymphangioma
Hypothyroidism
Acromegaly
Restrictive cardiomyopathy with peripheral neuropathy:
Infiltrative disorders:
Amyloidosis
Sarcoidosis
Neoplasia:
Lymphoma
Carcinomatosis
Storage disorders:
Fabry's disease
Haemochromatosis

The spongiform encephalopathies (Creutzfeldt-Jakob disease, kuru, etc) and the animal varieties such as bovine spongiform encephalopathy and scrapie are all characterised by amyloid plaques formed from prion proteins.

Senile cardiac amyloidosis

Transthyretin's inherent capacity to lay down amyloid fibrils explains why deposition commonly occurs in the ageing heart. ${ }^{32}$ Whereas transthyretin deposits in the ventricle, the atria may often have deposits derived from atrial naturetic or brain naturetic peptide. ${ }^{33}$ Although this deposition is rarely of clinical significance, senile amyloidosis may occasionally lead to massive deposition and heart failure. ${ }^{34}$

Identifying the patient with amyloidosis Patients have often run the gamut of medical specialties before a diagnosis of amyloidosis is reached. This is often because physicians tend to compartmentalise the symptoms with which they are presented as well as simply not considering this diagnosis. However, with the advent of effective treatment, the early identification of patients with amyloidosis has assumed greater importance.

(A) HISTORY AND EXAMINATION

Amyloidosis is a multisystem disorder and clinical involvement of a single organ is rare. A history with a combination of symptoms including fatigue, weight loss, easy bruising, rapid onset of breathlessness, peripheral oedema, sensory change (including carpal tunnel syndrome), or postural hypotension should arouse suspicion of the disease. A family history of unexplained "neuromuscular" disease may lead to a suspicion of the hereditary amyloidoses, a history of chronic haemodialysis would point to
$\mathrm{A} \beta 2 \mathrm{M}$ whereas a chronic inflammatory condition may suggest AA amyloidosis.

Amyloidosis should be suspected in those presenting with unexplained renal disease, especially the nephrotic syndrome, or those presenting with a restrictive cardiomyopathy. Coexistence of both conditions makes the disease likely. In AA amyloidosis, as well as the kidney, the liver is the predominant organ involved. Thus marked hepatomegaly in association with kidney disease must include amyloidosis in the differential.

Although the nephrotic syndrome may be a common manifestation of other systemic illnesses, the differential may be shortened by the fact that in amyloidosis massive proteinuria is often accompanied by normal or slightly enlarged kidneys (table 3). Furthermore, hypertension is rarely present even in the face of severe renal failure. The nephrotic syndrome also provides a clue to the type of amyloidosis as, although it is the commonest manifestation of $\mathrm{AL}$ and $\mathrm{AA}$ amyloidosis, it is rare in the familial forms of this disorder.

Predominantly right sided and rapidly progressive heart failure, often in the absence of a history of chest pain, which may be associated with a characteristic low voltage pattern on electrocardiography, suggests AL amyloidosis. Myocardial involvement in ATTR amyloidosis varies according to the specific transthyretin mutation (table 4). Cardiac involvement is rare in AA amyloidosis and if detected it rarely leads to heart failure. ${ }^{35}$

In the elderly, development of an infiltrative cardiomyopathy should lead to a suspicion of senile amyloidosis. In the elderly black population, heart failure with severe left ventricular hypertrophy may be due to hypertension but consideration should also be given to the Ile 122 syndrome that results in a similar appearance on echocardiography.

A sensory glove and stocking type polyneuropathy (motor neuropathy is rare) especially if associated with a carpal tunnel syndrome, vitreous opacities, ${ }^{36}$ or other major organ involvement should arouse suspicion of the hereditary amyloidoses where the neurological manifestations are prominent. The carpal tunnel syndrome may predate the diagnosis by months or even years. ${ }^{13}$ Symptoms or signs of an autonomic neuropathy such as postural hypotension or early satiety in combination with renal or cardiac involvement should also alert a physician. Although overt autonomic dysfunction may be found in a sixth of AL patients, ${ }^{37}$ subtle disturbances of autonomic function such as loss of heart rate variability, blood pressure variation, or pupillary abnormalities $^{38}$ are present in a significantly higher number of these patients.

Table 4 Hereditary syndromes and cardiac manifestations

\begin{tabular}{lllll}
\hline Mutation & Position & Found & Echo & Outcome \\
\hline Methionine for valine & 30 & Universally & Appearance may be normal & Conduction abnormalities \\
Alanine for threonine & 60 & Anglo-Saxon, Celts & Infiltrative cardiomyopathy (myocardium thickened) & Heart failure only slowly progressive \\
Isoleucine for valine & 122 & Blacks & Infiltrative cardiomyopathy & Heart failure \\
\hline
\end{tabular}

${ }^{\star}$ Left ventricular appearances may be similar to those seen in hypertension. 
Table 5 Laboratory findings that aid identification of amyloidosis

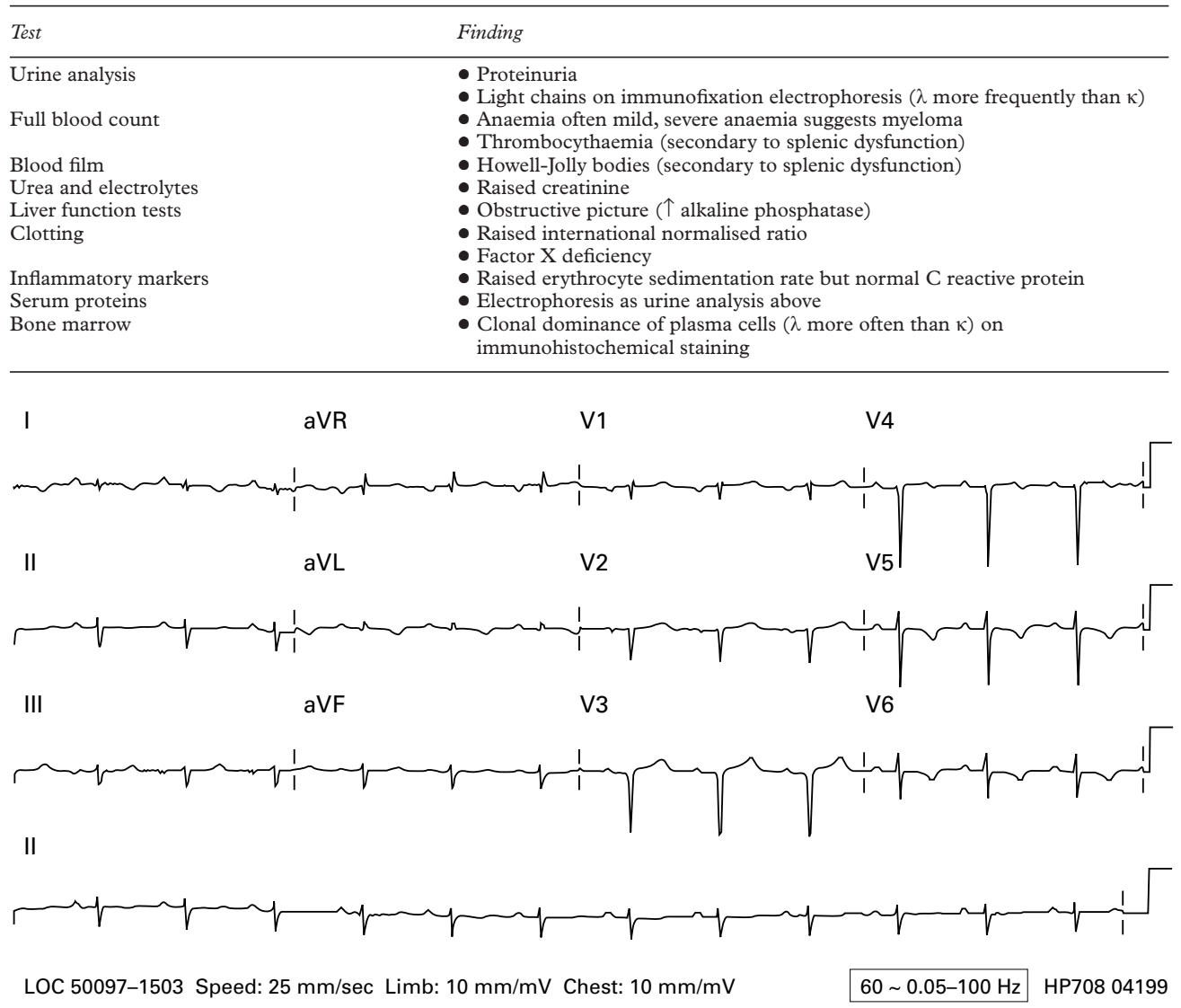

Figure 3 Electrocardiogram of a patient with cardiac amyloidosis showing decreased amplitude of the QRS complex in the limb leads and a pseudoinfarct pattern across the anterior leads. Conduction abnormalities including first degree heart block and left anterior fasicular block seen in this example are frequently present.

In the gut, there may be evidence of a change in bowel habit. This may be secondary to an autonomic disturbance but may also be due to direct infiltration of the bowels. Gastrointestinal haemorrhage is an uncommon feature of this infiltration. Hepatomegaly is a frequent finding, ${ }^{39}$ and although palpable splenomegaly is rare, evidence of splenic dysfunction is often apparent (table 5).

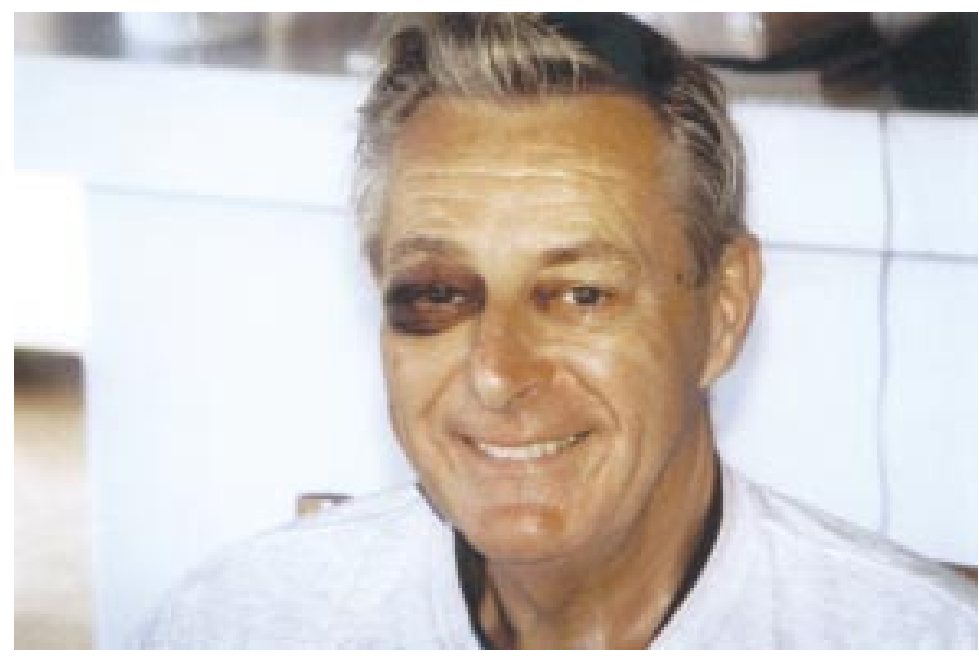

Figure 2 Right raccoon eye sign. Bruising around the eyes often provoked by minimal pressure such as rubbing ones eyes or even sneezing. Unlike in a traumatic haematoma, the purpura here is unassociated with swelling (photograph reproduced with patient's permission).
Macroglossia is a clue both to the diagnosis and to the fibril type, as it is almost specific to AL amyloidosis (table 3). The tongue is stiffened and often ringed by the indentation of teeth. Subcutaneous deposits, nail dystrophy, or even alopecia may result from soft tissue infiltration. ${ }^{40}$ Consider this diagnosis if the patient reports a change in voice or in the appreciation of food. ${ }^{41}$

There are few other conditions that will cause spontaneous periorbital purpura. ${ }^{42}$ The "raccoon eye sign" (fig 2) is a consequence of vascular fragility induced by the deposition of amyloid. Unexplained abnormal clotting indices should also alert one to the possibility of this condition, where a factor $\mathrm{X}$ deficiency may occur as a result of its binding to AL amyloid fibrils. $^{43}$

(B) LABORATORY TESTS

Laboratory investigations that may help identify a patient with amyloidosis are summarised in table 5 .

\section{(C) OTHER INVESTIGATIONS}

Electrocardiography and echocardiography

In the case of cardiac involvement, the diagnosis may also be suggested by an electrocardiogram or by echocardiography. As illustrated in fig 3, the electrocardiogram often shows a characteristic low voltage pattern (rather than 
the increased voltage that may be expected with left ventricular hypertrophy) that is associated with poor $\mathrm{R}$ wave progression across the limb leads (pseudoinfarct pattern). ${ }^{44}$

Echocardiograph appearances include biventricular thickening with a reduced cavity size. In severe disease the Doppler signal is of a restrictive filling pattern (rapid mitral "E" wave deceleration time). This may be associated in addition with a reduced "A" wave due to a combination of atrial infiltration and restriction to diastolic filling. ${ }^{45} \mathrm{~A}$ spiculated appearance of the myocardium and valvular thickening may also be present.

\section{Radionuclide studies}

Although they may be used in diagnosis, ${ }^{7}$ radionuclide studies are most often performed to assess the extent of deposition. Quantific scintigraphy is provided by labelling the amyloid P component with 123-iodine, the serum amyloid P scan. ${ }^{76}$ This can be used to follow progress after treatment and has also helped elucidate patterns of distribution in the different forms of the disease. ${ }^{47} 48$ The technique has enabled other important observations including the fact that deposits, as opposed to being fixed, are actually in a state of flux. ${ }^{49}$ This helps explain why abolishing the

History and examination

Biopsy of affected organ

sample of subcutaneous abdominal fat

Confirmed by Congo red histology

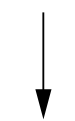

Immunofixation electrophoresis of serum or urine/ immunohistochemical staining of BM

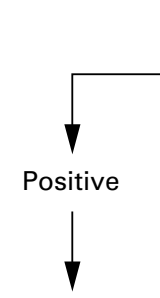

AL amyloidosis

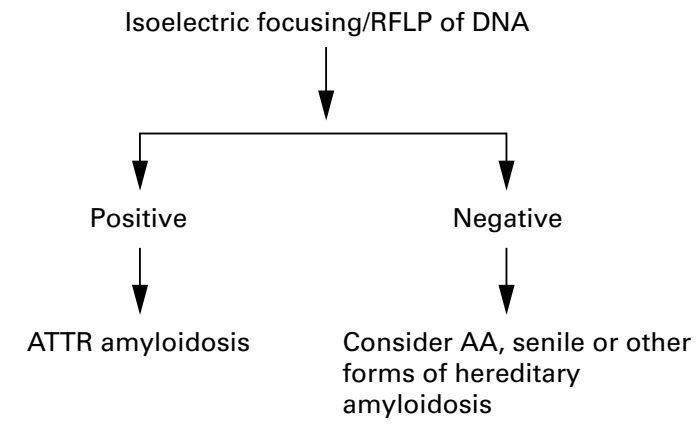

Figure 4 Diagnosis $(B M=$ bone marrow; $R F L P=$ restriction fragment length polymorphism). supply of fibril precursor protein leads to clinical evidence of organ improvement.

Serum amyloid $\mathrm{P}$ scans are costly and not widely available. Technetium aprotonin binds to many forms of amyloid and is also a useful radionuclide agent, although it does not provide quantitative scintigraphy.

\section{Diagnosis}

To establish the diagnosis of amyloidosis requires histological confirmation of clinical suspicion (fig 4). Although an affected organ (for example the kidney) is often biopsied, more risky procedures can be avoided by simple subcutaneous aspiration of abdominal fat using a wide bore needle and syringe. ${ }^{50} 51$ This carries the advantage over other widely used methods such as rectal biopsy, in that it is less invasive but at least as effective.

The tissue obtained is then subjected to Congo red staining which, if positive, confirms the presence but not the type of amyloid. AL being the most common, immunofixation electrophoresis of serum or urine is undertaken to search for a clonal disorder (fig 1). In the case of a negative result, immunohistochemical staining of a bone marrow specimen to search for $\kappa$ or $\lambda$ light chains should be performed. The specific type of amyloid fibril can also be identified by light and electron microscopy of labelled antibodies using immunogold staining. This has also been shown to be of use in identifying mixed forms of amyloidosis. ${ }^{52}$

In the absence of a plasma cell dyscrasia, a variant transthyretin should be sought by isoelectric focusing of the serum, which will separate variant from wild-type transthyretin. ${ }^{53}$ In such a case, genetic testing should be undertaken as the specific mutation affects prognosis and management. ${ }^{36}$

AA amyloidosis is suspected in patients with a chronic inflammatory condition in whom AL and ATTR amyloidosis have been excluded. Confirmation of the diagnosis is then made by immunohistochemical staining for the AA protein. $^{54}$

\section{Prognosis}

The prognosis depends on the specific type of amyloidois and on the organs involved. Untreated AL amyloidosis carries the worst prognosis with a median survival of one to two years ${ }^{37}$ with cardiac involvement predicting the worst outcome. Patients with ATTR amyloidosis may survive up to 15 years from diagnosis but this time also varies with the specific mutation and the time of diagnosis- the younger the age of presentation the worse the outcome. The prognosis of patients with AA is affected by the underlying condition.

\section{Treatment}

From being a uniformly fatal disease, treatment is now available for amyloidosis patients extending event free and overall survival especially if the supply of precursor protein can be terminated..$^{45}$ This is more difficult to achieve in some forms of the disease but a body of evidence is gradually accruing about the most effective modes of therapy. In addition to 
attempting to cure the underlying condition, significant advances in the supportive therapy of these patients has also led to the improvement in their prognosis as well as in their quality of life years.

\section{Supportive management}

Optimal management is tailored to the specific requirements of the patient. Even simple measures such as antigravity stockings for postural hypotension or night-lights in the case of peripheral neuropathy can alleviate symptoms and improve quality of life. In heart failure vigorous diuretic therapy is indicated and should be titrated to the patient's symptoms and renal function. The use of angiotensin converting enzyme inhibitors requires extreme caution especially in the case of orthostatic hypotension. Calcium channel antagonists, which may be given mistakenly to treat diastolic dysfunction, exarcerbate the condition ${ }^{56}$ and $\beta$ blockers are best avoided due to their negative inotropism. Digoxin is contraindicated as it avidly binds to amyloid fibrils causing toxicity. ${ }^{57}$ Pacemaker insertion may be indicated for conduction abnormalities or symptomatic bradycardia.

With renal involvement, dialysis prolongs life and may be necessary to support the patient through an aggressive treatment regimen or until transplantation..$^{58}$ Gastric paresis is aided by motility agents and treating a blind loop syndrome should be considered in the case of malabsorption, although an autonomic neuropathy causing similar symptoms should be ruled out first. Some of the more recent strategies to alleviate other effects of autonomic neuropathy include:

- Midodrine-an $\alpha$ agonist, midodrine benefits patients with postural hypotension..$^{59}$ Our experience suggests that in comparison to nonamyloid postural hypotension, more rapid titration and higher eventual doses are often required but symptom relief can be profound.

- Erythropoietin - if there is evidence of a mild anaemia or a decreased red cell mass erythropoietin may also provide symptom relief to those with orthostasis. ${ }^{60}$

\section{Treatment of the underlying condition}

AL AMYLOIDOSIS

Although there are data suggesting an improvement in survival in AL patients treated with colchicine compared with retrospective controls, ${ }^{61}$ this has not been borne out when compared with chemotherapeutic agents. Three trials have now shown the superiority of the alkylating agent, melphalan, with prednisolone over colchicine in AL patients. ${ }^{62-64}$ However, the response rate to the melphalan combination is low with a median increase in survival of approximately six months. Patients must also live long enough to receive several cycles of melphalan before a survival benefit occurs.

The aim of treatment being the eradication of the amyloidogenic clone, ${ }^{55}$ chemotherapeutic regimens successful for plasma cell eradication in myeloma have been applied to AL patients. Vincristine, Adriamycin, and dexamethasone have been used with evidence of response in a cohort of patients. ${ }^{65}$ Although still undergoing open trial, the treatment of choice is now believed to be high dose melphalan with autologous bone marrow stem cell transplantation. This regimen has resulted in the complete remission of the amyloidogenic clone in almost half of treated patients (cumulative experience of 250 patients; V Sanchorawala, personal communication) and prolonged survival in those treated but not in remission. ${ }^{66}{ }^{67}$ Median survival of patients in complete remission has not been reached after six years of follow up.

Treatment with 4'-iodo-4'-deoxydorubicin, an anthracycline derivative, shown to bind amyloid fibrils in vitro and believed to decrease fibril deposition, was initially reported with some success, ${ }^{68}$ but more recently it has not been shown to have long term efficacy. ${ }^{69}$

The treatment of AL amyloidosis restricted to specific organs by transplantation and subsequent chemotherapy is also under consideration. In cases limited to the heart, cardiac transplantation has been performed but progression of the disease and recurrence in the transplanted organ have limited this approach. However organ transplantation with subsequent chemotherapy to induce remission is currently under investigation..$^{71}$

As the search for the definitive therapeutic regimen continues, options for the future include:

- Thalidomide-possibly through antiangiogenic and immunomodulatory mechanisms, thalidomide has recently been shown to be effective as treatment for refractory multiple myeloma. ${ }^{72}$ Its use in $\mathrm{AL}$ amyloidosis is currently being considered.

- Etarnacept-inflammatory cytokines, especially $\mathrm{TNF}-\alpha$, are believed to play a part in the pathogenesis of amyloidosis. Early data using a TNF receptor antagonist have shown some beneficial symptomatic response in patients with cardiac involvement. ${ }^{73}$

\section{HEREDITARY AMYLOIDOSIS}

Transthyretin is almost exclusively synthesised by hepatocytes, which led to the suggestion of liver transplantation as therapy for familial amyloidotic polyneuropathies. ${ }^{74}$ After transplantation, the successful disappearance of circulating mutant transthyretin with associated symptomatic improvement was confirmed. ${ }^{47} 75$ This has led to liver transplantation becoming the definitive treatment for ATTR associated familial amyloidotic polyneuropathies. The organ being removed often has normal function and is increasingly being used in domino procedures to recipients whose morbidity requires immediate organ donation but makes them less able to receive regular organs. ${ }^{76-78}$ Due to the fact that the onset and progression of the amyloidosis depends on the specific mutation involved, optimal timing for transplantation requires careful assessment.

\section{AA AMYLOIDOSIS}

Waldenstrom presented the first evidence of regression of organomegaly secondary to amyloid after surgical treatment of tuberculous 
osteomyelitis. ${ }^{79}$ Other effective forms of treating the underlying chronic inflammatory response include colchicine in familial Mediterranean fever ${ }^{80} 81$ and chlorambucil in juvenile rheumatoid arthritis. ${ }^{82}$

\section{DIALYSIS RELATED AMYLOIDOSIS}

The definitive treatment is renal transplantation, ${ }^{83}$ which provides dramatic symptom relief despite the fact that the associated amyloid continues to be histologically present for several years. ${ }^{84}$

\section{Conclusion}

There has been a recent vast increase in the understanding and treatment of patients with amyloidosis. An increased clinical awareness among physicians about this disorder, the investigations required to pursue its diagnosis, and the therapeutic options currently available is necessary for the benefit to impact on patients.

1 Wilks $S$. Cases of lardaceous disease and some allied affections, with remarks. Guy's Hosp Rep 1856;2:103-32.

2 Cohen AS. History of amyloidosis. F Intern Med 1992;232 509-10.

3 Bennhold H. Eine spezifische Amyloidfarbung mit Kongorot. Munch Med Wochenschr 1922;69:1537-8.

4 Cohen AS. Electron microscopic observations on a fibrous component in amyloid of diverse origins. Nature 1959;183 $1202-3$

5 Shirahama T, Cohen AS. High-resolution electron microscopic analysis of the amyloid fibril. 7 Cell Biol 1967;33:679708.

6 Bonar L, Cohen AS, Skinner M. Characterization of the amyloid fibril as a cross-beta protein. Proc Soc Exp Biol Med 1969;131:1373-5.

7 Hawkins PN, Myers MJ, Epenetos AA, et al. Specific localization and imaging of amyloid deposits in vivo using zation and imaging of amyloid deposits in vivo using 167:903-13.

8 Axelrad MA, Kisilevsky R, Willmer J, et al. Further characerization of amyloid-enhancing factor. Lab Invest 1982;47 $139-46$

9 Kisilevsky R. Proteoglycans, glycosaminoglycans, amyloidnhancing factor, and amyloid deposition. F Intern Med 1992;232:515-6.

10 Husby G. A chemical classification of amyloid. Correlation with different clinical types of amyloidosis. Scand 7 Rheumatol 1980;9:60-4.

11 Falk RH, Comenzo RL, Skinner M. The systemic amyloidoses. N Engl f Med 1997;337:898-909.

12 Glenner GG, Terry W, Harada M, et al. Amyloid fibril proteins: proof of homology with immunoglobulin light proteins: proof of homology with immunoglobulin

13 Falk RH, Skinner M. The systemic amyloidoses: an overview. Adv Intern Med 2000;45:107-37.

14 Kyle RA, Greipp PR, O'Fallon WM. Primary systemic amyloidosis: multivariate analysis for prognostic factors in 68 cases. Blood 1986;68:220-4.

15 Benditt E, Eriksen N, Hermodson M, et al. The major proteins of human and monkey amyloid substance: common properties including unusual N-terminal amino acid sequences. FEBS Lett 1971;19:169-73.

16 Skinner M. Protein AA/SAA. F Intern Med 1992;232:513-4

17 Westermark GT, Engstrom U, Westermark P. The $\mathrm{N}$-terminal segment of protein AA determines its fibrillogenic property. Biochem Biophys Res Commun 1992;182:2733.

18 Snow AD, Kisilevsky R. Temporal relationship between glycosaminoglycan accumulation and amyloid deposition durcosaminoglycan accumulation and amyloid deposition during experimental amy

19 Hawkins PN, Richardson S, Vigushin DM, et al. Serum amyloid $\mathrm{P}$ component scintigraphy and turnover studies for diagnosis and quantitative monitoring of AA amyloidosis in juvenile rheumatoid arthritis. Arthritis Rheum 1993;36:84251

20 Gertz MA, Kyle RA. Secondary systemic amyloidosis: response and survival in 64 patients. Medicine 1991;70:24656

21 Nichols WC, Dwulet FE, Liepnieks J, et al. Variant apolipoprotein $\mathrm{AI}$ as a major constituent of a human hereditary amyloid. Biochem Biophys Res Commun 1988;156:762-8.

22 Benson MD, Liepnieks J, Uemichi T, et al. Hereditary renal amyloidosis associated with a mutant fibrinogen alphachain. Nat Genet 1993;3:252-5.

23 Maury CP, Kere J, Tolvanen R, et al. Finnish hereditary amyloidosis is caused by a single nucleotide substitution in the gelsolin gene. FEBS Letters 1990;276:75-7.
24 Benson MD, Uemichi T. Transthyretin amyloidosis. Amyloid-International fournal of Experimental \& Clinical Investigation 1996;3:44-56.

25 Costa PP, Figueira AS, Bravo FR. Amyloid fibril protein related to prealbumin in familial amyloidotic polyneuropathy. Proc Natl Acad Sci U S A 1978;75:4499-503.

26 Wallace MR, Dwulet FE, Conneally PM, et al. Biochemical and molecular genetic characterization of a new variant prealbumin associated with hereditary amyloidosis. 7 Clin Invest 1986;78:6-12.

27 Jacobson DR, Pastore RD, Yaghoubian R, et al. Variantsequence transthyretin (isoleucine 122) in late-onset cardiac amyloidosis in black Americans. N Engl f Med 1997;336: 466-73.

28 Jacobson DR, Pastore R, Pool S, et al. Revised transthyretin Ile 122 allele frequency in African-Americans. Hum Genet 1996;98:236-8

29 Gejyo F, Yamada T, Odani S, et al. A new form of amyloid protein associated with chronic hemodialysis was identified as beta 2-microglobulin. Biochem Biophys Res Commun 1985;129:701-6.

30 Glenner GG, Wong CW. Alzheimer's disease: initial report of the purification and characterization of a novel cerebrovascular amyloid protein. Biochem Biophys Res Commun 1984;120:885-90.

31 Scheuner D, Eckmann C, Jensen M, et al. Secreted amyloid beta-protein similar to that in the senile plaques of Alzeimer's disease is increased in vivio by the presenilin 1 and 2 and
APP mutations linked to familial Alzheimer's disease. Nat Med 1996;2:864-70.

32 Reisinger J, Dubrey S, Falk R. Cardiac amyloidosis. Cardiology in Review 1997;5:317-25.

33 Pucci A, Wharton J, Arbustini E, et al. Atrial amyloid deposits in the failing human heart display both atrial and brain natriuretic peptide-like immunoreactivity. $f$ Pathol 1991; 165:235-41.

34 Olson LJ, Gertz MA, Edwards WD, et al. Senile cardiac amyloidosis with myocardial dysfunction. Diagnosis by endomyocardial biopsy and immunohistochemistry. N Engl endomyocardial biopsy and

35 Dubrey SW, Cha K, Simms RW, et al. Electrocardiography and Doppler echocardiography in secondary (AA) amyloidosis. Am 7 Cardiol 1996; 77:313-5.

36 Benson MD. Amyloidosis. In: Scriver CR, Beudet AL, Sly WS, et al, eds. The metabolic and molecular bases of inherited disease. 7th Ed. New York: McGraw-Hill, 1995: 4159-91.

37 Kyle RA, Gertz MA. Primary systemic amyloidosis: clinica and laboratory features in 474 cases. Semin Hematol 1995;32:45-59.

38 Davies DR, Smith SE. Pupil abnormality in amyloidosis with autonomic neuropathy. F Neurol Neurosurg Psychiatry 1999;67:819-22

39 Lovat LB, Persey MR, Madhoo S, et al. The liver in systemic amyloidosis: insights from 123I serum amyloid $\mathrm{P}$ component scintigraphy in 484 patients. Gut 1998;42:727-34.

40 Wheeler GE, Barrows GH. Alopecia universalis. A manifestation of occult amyloidosis and multiple myeloma. Arch Dermatol 1981;117:815-6.

41 Marinone MG, Merlini G. Reduced taste perception in AL amyloidosis. A frequently unnoticed sensory impairment. Haematologica 1996;81:110-5.

42 Bolognia JL, Braverman IM. Skin manifestations of internal disease. In: Fauci AS, Braunwald E, Isselbacher KJ, et al, eds. Harrison's principles of internal medicine. 14th Ed. New York: McGraw-Hill, 1998: 310-28.

43 Furie B, Greene E, Furie BC. Syndrome of acquired factor $\mathrm{X}$ deficiency and systemic amyloidosis in vivo studies of the metabolic fate of factor X. N Engl F Med 1977;297:81-5.

44 Reisinger J, Dubrey SW, Lavalley M, et al. Electrophysiologic abnormalities in AL (primary) amyloidosis with carologic abnormalities in AL (primary) amyloidosis with

45 Klein AL, Hatle LK, Burstow DJ, et al. Doppler characterization of left ventricular diastolic function in cardiac amyloidosis. F Am Coll Cardiol 1989;13:1017-26.

6 Hawkins PN, Pepys MB. Imaging amyloidosis with radiolabelled SAP. Eur F Nucl Med 1995;22:595-9

47 Holmgren G, Ericzon BG, Groth CG, et al. Clinical improvement and amyloid regression after amyloid transplantation in hereditary transthyretin amyloidosis. Lancet 1993;341:1113-6.

48 Pepys MB. Amyloid P component and the diagnosis of amyloidosis. F Intern Med 1992;232:519-21.

49 Hawkins PN, Richardson S, Macsweeney JE, et al. Scintigraphic quantification and serial monitoring of human visceral amyloid deposits provide evidence for turnover and regression. $O 7 \mathrm{Med} 1993 ; \mathbf{8 6}: 365-74$.

50 Libbey CA, Skinner M, Cohen AS. Use of abdominal fat tissue aspirate in the diagnosis of systemic amyloidosis. Arch Intern Med 1983;143:1549-52.

51 Duston MA, Skinner M, Shirahama T, et al. Diagnosis of amyloidosis by abdominal fat aspiration. Analysis of four years' experience. Am f Med 1987;82:412-4.

52 Arbustini E, Morbini P, Verga L, et al. Light and electron microscopy immunohistochemical characterization of amyloid deposits. Amyloid-International fournal of Experimental E Clinical Investigation 1997;4:157-70.

53 Altland K, Banzhoff A. Seperation of hybrid isoelectric fousing of normal human plasma transthyretin (prealbu$\mathrm{min}$ ) and a variant with a methionine for valine substitution associated with familial amyloidotic polyneuropathy. Electrophoresis 1986;7:529-33.

54 Shirahama T, Cohen AS, Skinner M. Immunohistochemistry of amyloid. In: DeLellis RA, ed. Advances in immunohistochemistry. New York: Masson, 1984: 277-302. 
55 Merlini G. Treatment of primary amyloidosis. Semin Hematol 1995;32:60-79.

56 Gertz MA, Falk RH, ive heart failure in amyloi channel-blocking agents. Am f Cardiol 1985;55:1645.

57 Rubinow A, Skinner M, Cohen AS. Digoxin sensitivity in amyloid cardiomyopathy. Circulation 1981;63:1285-8.

58 Skinner M. Amyloidosis. In: Lichtenstein LM, Fauci AS, eds. Current therapy in allergy, immunology, and rheumatology. St Louis: Mosby, 1996: 235-40.

59 Low PA, Gilden JL, Freeman R, et al. Efficacy of midodrine versus placebo in neurogenic orthostatic hypotension: a ran-
domised, double-blind multicenter study. $\mathscr{f} A M A$ 1997;277: 1046-51.

60 Hoeldtke RD, Streeten DHP. Treatment of orthostatic hypotension with erythropoietin. N Engl F Med 1993;329: 611-15.

61 Cohen AS, Rubinow A, Anderson JJ, et al. Survival of patients with primary (AL) amyloidosis. Colchicine-treated cases from 1976 to 1983 compared with cases seen in previous years (1961 to 1973). Am f Med 1987;82:1182-90.

62 Kyle RA, Greipp PR, Garton JP, et al. Primary systemic amyloidosis. Comparison of melphalan/prednisone versus colchicine. Am f Med 1985;79:708-16.

63 Skinner M, Anderson J, Simms R, et al. Treatment of 100 patients with primary amyloidosis: a randomized trial of melphalan, prednisone, and colchicine versus colchicine only. Am f Med 1996;100:290-8.

64 Kyle RA, Gertz MA, Greipp PR, et al. A trial of three regimens for primary amyloidosis: colchicine alone, melphalan and prednisone, and melphalan, prednisone, and colchicine. N Engl F Med 1997;336:1202-7.

65 Persey MR, Lovat LB, Apperley JF, et al. Intensive chemotherapy for AL amyloidosis. Br F Rheumatol 1996; 35(suppl 1):12.

66 Comenzo RL, Vosburgh E, Simms RW, et al. Dose-intensive melphalan with blood stem cell support for the treatment of AL amyloidosis: one-year follow-up in five patients. Blood 1996;88:2801-6.

67 Comenzo RL, Vosburgh E, Falk RH, et al. Dose-intensive melphalan with blood stem-cell support for the treatment of melphalan with blood stem-cell support for the treatment of AL (amyloid light-chain) amyloidosis: survival

68 Merlini G, Ascari E, Amboldi N, et al. Interaction of the anthracycline 4'-iodo-4'-deoxydoxorubicin with amyloid fibrils: inhibition of amyloidogenesis. Proc Natl Acad Sci U S A 1995;92:2959-63.
69 Merlini G, Anesi E, Garini P, et al. Treatment of AL amyloidosis with 4'-iodo-4'-deoxydoxorubicin: an update. 1999:93:1112-13.

70 Hall R, Hawkins PN. Cardiac transplantation for AL amyloidosis. BMF 1994;309:1135-7.

71 Dubrey S, Falk RH. Heart transplantation in AL amyloidosis. Amyloid-International fournal of Experimental \& Clinical Investigation 1995;2:284-287.

72 Singhal S, Mehta J, Desiken R, et al. Antitumor activity of thalidomide in refractory multiple myeloma. $N \mathrm{Engl} F \mathrm{Med}$ 1999;341:1565-71.

73 Juturi J, Karam MA, McLain DA, et al. Therapy with TNF-r Enbrel ${ }^{\circledR}$ results in remarkable symptom relief in patients (pts) with advanced primary amyloidosis (AL) [abstract]. Blood 1999;94 (suppl 1):314a.

74 Holmgren G, Steen L, Ekstedt J, et al. Biochemical effect of liver transplantation in two Swedish patients with familial amyloidotic polyneuropathy (FAP-met30). Clin Genet 1991; 40:242-6.

75 Skinner M, Lewis WD, Jones L, et al. Liver transplantation as a treatment for familial amyloidotic polyneuropathy. Ann Intern Med 1994;120:133-4.

76 Azoulay D, Sameul D, Castaing D, et al. Domino liver transplants for metabolic disorders: experiance with familial amyloidotic polyneuropathy. F Am Coll Surg 1999;189:584 93.

77 Schmidt HHJ, Nashan B, Propsting MJ, et al. Familial amyloidotic polyneuropathy: domino liver transplantation. $\mathcal{F}$ Hepatol 1999;30:293-8.

78 Hemming AW, Cattral MS, Greig PD, et al. Domino liver transplantation for familial amyloid polyneuropathy: optimal use of a scarce resource. Transplant Proc 1999;31:515.

79 Waldenstrom $\mathrm{H}$. On the formation and disappearance of amyloid in man. Acta Chir Scand 1928;63:479-530.

80 Ravid M, Robson M, Kedar I. Prolonged colchicine treatment in four patients with amyloidosis. Ann Intern Med 1977;87:568-70.

81 Zemer D, Pras M, Sohar E, et al. Colchicine in the prevention and treatment of the amyloidosis of familial Mediterranean fever. N Engl 7 Med 1986;314:1001-5.

82 David J. Amyloidosis in juvenile chronic arthritis. Clin Exp Rheumatol 1991;9:73-8.

83 Koch KM. Dialysis-related amyloidosis. Kidney Int 1992;41: 1416-29.

84 Nelson SR, Sharpstone P, Kingswood JC. Does dialysisassociated amyloidosis resolve after transplantation? Nephrol Dial Transplant 1993;8:369-70. 